Check for updates

Cite this: RSC Adv., 2019, 9, 14400

Received 25th December 2018 Accepted 10th April 2019

DOI: 10.1039/c8ra10554e

rsc.li/rsc-advances

\section{[HDMF]Cl-based DES as highly efficient extractants and catalysts for oxidative desulfurization of model oil}

\begin{abstract}
Rong-xiang Zhao, Xiu-ping Li, (D) * Chun-feng Mao, (D) Liangpei Hou and Xiaohan Gao
$N, N$-Dimethylformamide hydrochloric acid/XMCl $([\mathrm{HDMF}] \mathrm{Cl} / \mathrm{XMCl}, \mathrm{M}=\mathrm{Zn}$ or Fe, $n=2$ or 3) was synthesized by stirring the mixture of [HDMF]Cl and metal chloride. [HDMF]Cl-based DES was characterized by FT-IR spectroscopy, ESI-MS and ${ }^{1} \mathrm{H}-\mathrm{NMR}$ spectroscopy. The oxidative desulfurization activity was investigated using [HDMF]Cl/0.2 $\mathrm{FeCl}_{3}$ and $[\mathrm{HDMF}] \mathrm{Cl} / \mathrm{ZnCl}_{2}$ as the extractant and catalyst, and hydrogen peroxide $\left(\mathrm{H}_{2} \mathrm{O}_{2}\right)$ as the oxidant. The desulfurization rate can reach up to $98.08 \%$ and 99.2\% for DBT using [HDMF]Cl/0.2 $\mathrm{FeCl}_{3}$ and $[\mathrm{HDMF}] \mathrm{Cl} / \mathrm{ZnCl}_{2}$, respectively. After recycling for 7 times, the removal rate of DBT still can reach more than $97 \%$.
\end{abstract}

\section{Introduction}

Ultra-desulfurization of gasoline and diesel oil is important because the sulfur compounds have brought many negative influences on the weather and health. Many countries have formulated strict environmental regulations to limit the sulfur content in the fuels (sulfur content $<10 \mathrm{ppm}$ ). ${ }^{1,2}$

In order to remove organic sulfur from petroleum products, the hydrodesulfurization (HDS) technology ${ }^{3}$ has been widely applied in the refining enterprises. However, HDS needs strict operating conditions, ${ }^{4}$ such as high temperature and high pressure, which result in the increase in the operational cost. Meanwhile, it is difficult to remove dibenzothiophene (DBT) and its derivatives due to space hindrance. ${ }^{5}$ In order to overcome the shortcomings of HDS, some non-HDS technologies such as adsorption desulfurization (ADS), ${ }^{6,7}$ oxidative desulfurization (ODS) ${ }^{8-10}$ biological desulfurization (BDS) ${ }^{11}$ and extractive desulfurization ${ }^{12}$ have been widely investigated. Among them, the oxidative desulfurization has become a hot topic because of its potential advantages such as mild reaction conditions and high desulfurization rate for dibenzothiophene (DBT) and its derivatives. In the oxidative desulfurization process, sulfur is oxidized into sulfone by oxidants such as molecular oxygen, ${ }^{13} \mathrm{H}_{2} \mathrm{O}_{2},{ }^{14} \mathrm{NO}_{2}$ (ref. 15) and substitute solid. ${ }^{16}$ Among these, $\mathrm{H}_{2} \mathrm{O}_{2}$ is a widely used oxidant because of its economic and environmental benefits.

DES as an ionic liquid is composed of a cation and an anion, and has some desirable properties ${ }^{17-20}$ such as excellent solubility, non-volatility, and non-flammability. Moreover, DES containing hydrogen bonding networks is liquid at room

College of Chemistry, Chemical Engineering and Environmental Engineering, Liaoning Shihua University, Fushun 113001, China.E-mail: zylhzrx@126.com; lilili_171717@ 126.com temperature. DES as an environment-friendly solvent is applied in synthesis ${ }^{21}$ catalysis ${ }^{22}$ separation ${ }^{23}$ and electrochemistry. ${ }^{24}$ In last several years, DES has been applied to the desulfurization process due to higher desulfurization rate. ${ }^{25-28}$ For instance, Li et al. ${ }^{29}$ synthesized $1.6 \mathrm{Et}_{3} \mathrm{NHCl} \cdot \mathrm{FeCl}_{3}$ extract, which facilitated the desulfurization rate up to $87 \%$. Chen et al. ${ }^{30}$ reported that $[\mathrm{Hnmp}] \mathrm{Cl} / \mathrm{ZnCl}_{2}$ was applied in oxidative desulfurization and its desulfurization rate reached up to $99.9 \%$ for the model diesel oil. Li et al. ${ }^{31}$ reported that $\mathrm{C}_{5} \mathrm{H}_{9} \mathrm{NO} \cdot 0.3 \mathrm{FeCl}_{3}$ was used as an extractant as well as a catalyst in ODS and the removal rate of DBT was $97 \%$ in $3 \mathrm{~h}$. Chen et al. ${ }^{32}$ synthesized $\left[\mathrm{C}_{4} \mathrm{mim}\right] \mathrm{Cl} / 3 \mathrm{ZnCl}_{2}$ and $99.9 \%$ sulphur-removal rate could be obtained. Dong et al. $^{33}$ found that the removal rate of DBT can reach up to $100 \%$ using $\left[\mathrm{C}_{6}{ }^{3} \mathrm{MPy}\right] \mathrm{Cl} / \mathrm{FeCl}_{3}$ as extractants and catalysts in ODS. In the process of desulfurization of oil, $\mathrm{N}, \mathrm{N}$ dimethylformamide (DMF) is often selected as an effective extractant. ${ }^{34,35}$ However, it is difficult to industrialize because the DMF dosage is too large. In this work, [HDMF]Cl-based DES is synthesized by a simple method. A small amount of DES used as catalysis and extractant in the oxidative desulfurization system can significantly improve desulfurization activity. The effects of the molar ratio of [HDMF]Cl to $\mathrm{MCl}_{n}$, temperature, oxygen to sulfur $(\mathrm{O} / \mathrm{S})$ molar ratio, amount of DES, and types of sulfur on the desulfurization activity were studied. The mechanism of desulfurization was investigated.

\section{Experiment}

\subsection{Materials}

2.1.1 Chemicals. DBT (98\%), 4,6-dimethyldibenzothiophene (4,6-DMDBT, 97\%), benzothiophene (BT, 99\%) and thiophene (TH, 99\%) were purchased from Aladdin reagent. $\mathrm{N}$ Octane, $\mathrm{HCl}, \mathrm{C}_{3} \mathrm{H}_{7} \mathrm{NO}, \mathrm{FeCl}_{3}, \mathrm{ZnCl}_{2}, \mathrm{H}_{2} \mathrm{O}_{2}(\mathrm{AR}, 30 \mathrm{wt} \%)$ and $\mathrm{CCl}_{4}$ 
(99\%) were purchased from Tianjin Damao Chemical Reagent Factory.

2.1.2 Instruments. Gas chromatography was performed on an Agilent 7890A GC with an FID detector using a $30 \mathrm{~m}$ packed HP5 column. Oxidation products of DBT, DBT, DES and the raw materials were characterized by Fourier-transform infrared spectroscopy (WQF-520; Beijing Bei-fen Ruili Analytical Instrument Co., Ltd, China) and ESI-MS using the Bruker Daltonics APEX-II (Bruker Daltonics Inc, USA).

\subsection{Synthesis}

2.2.1 Preparation of [HDMF]Cl. $\mathrm{HCl}(36 \%)$ was added to $N, N$-dimethylformamide at a molar ratio of $1: 1$ and stirred for 3 hours at $50{ }^{\circ} \mathrm{C}$. Water in the solution was removed by rotary evaporation after stirring. Finally, the $[\mathrm{HDMF}] \mathrm{Cl}$ solution was obtained.

2.2.2 Preparation of $[\mathrm{HDMF}] \mathrm{Cl} / \mathrm{XMCl}_{n}$. $[\mathrm{HDMF}] \mathrm{Cl}$ and $\mathrm{MCl}_{n}$ were added into a $100 \mathrm{~mL}$ cylindrical vessel. The mixture was heated in air with stirring using a glass rod until the complete dissolution of the compounds resulted in a transparent and viscous liquid. $[\mathrm{HDMF}] \mathrm{Cl} / \mathrm{XMCl}_{n}$ was obtained. The synthetic mechanism of DES is shown in Fig. 1.

\subsection{Desulfurization experiment}

Model oil (500 $\mu \mathrm{g} \mathrm{g}^{-1}$ ) was prepared by dissolving $1.437 \mathrm{~g}$ DBT in $500 \mathrm{~mL} n$-octane. To implement the ODS process, the model oil, DES and $30 \mathrm{wt} \% \mathrm{H}_{2} \mathrm{O}_{2}$ were added into a three-necked flask. The mixture was stirred at $50 \mathrm{rpm}$ in a water bath at a particular temperature. The oil taken out from the upper layer in every 20 min was analyzed by gas chromatography on an Agilent 7890A GC with an FID detector using a $30 \mathrm{~m}$ packed HP5 column. The removal rate was calculated by the formula:

$$
\text { Sulfur removal rate }=\frac{S_{\mathrm{tot}}-S_{\mathrm{res}}}{S_{\mathrm{tot}}} \times 100 \%
$$

where $S_{\text {tot }}\left(500 \mu \mathrm{g} \mathrm{g}^{-1}\right)$ is the total content of the sulfur compound in the model oil, $S_{\text {res }}$ is the residual content of the sulfur compound after the ODS process.

\section{Results and discussion}

\subsection{ESI-MS spectra of $[\mathrm{HDMF}] \mathrm{Cl} \cdot \mathrm{0.2FeCl}_{3}$}

In order to determine the structures of $[\mathrm{HDMF}] \mathrm{Cl} \cdot 0.2 \mathrm{FeCl}_{3}$ and $[\mathrm{HDMF}] \mathrm{Cl} / \mathrm{ZnCl}_{2}$, the ESI-MS spectra of [HDMF $] \mathrm{Cl} \cdot 0.2 \mathrm{FeCl}_{3}$ and $[\mathrm{HDMF}] \mathrm{Cl} / \mathrm{ZnCl}_{2}$ were obtained. The results are shown in Fig. 2. From the ESI-MS spectrum of $[\mathrm{HDMF}] \mathrm{Cl} \cdot 0.2 \mathrm{FeCl}_{3}$, the peaks observed at $m / z=163$ and 198 correspond to $\mathrm{FeCl}_{3}$ and $\mathrm{FeCl}_{4}{ }^{-}$, respectively. The peak at $m / z=201$ can be attributed to [HDMF] $\mathrm{FeCl}_{2}{ }^{+}$. The peaks at $m / z=163$ and 198 correspond to those in a previous report. ${ }^{29,30}$ The peak at $m / z=201$ demonstrates that there is a reaction between $[\mathrm{HDMF}] \mathrm{Cl}$ and $\mathrm{FeCl}_{3}$. The lone pair electrons of $\mathrm{N}$ in [HDMF] and an unoccupied orbital of $\mathrm{Fe}$ in $\mathrm{FeCl}_{3}$ form a covalent bond. $4 \mathrm{~mol}$ of [HDMF] supplies four electrons and 1 mol Fe supplies four half-unoccupied orbitals resulting in the molar ratio of $4: 1$ for [HDMF]Cl and $\mathrm{FeCl}_{3}$. Fig. 2(b) also shows that peaks of $\mathrm{ZnCl}_{3}{ }^{-}, \mathrm{Zn}_{2} \mathrm{Cl}_{5}{ }^{-}$and $\mathrm{Zn}_{3} \mathrm{Cl}_{7}{ }^{-}$ appeared at $m / z 171,307$ and 448. However, these peaks cannot verify the reaction between $[\mathrm{HDMF}] \mathrm{Cl}$ and $\mathrm{ZnCl}_{2}$. The ESI-MS spectrum of the cation is shown in Fig. 2(c). The peaks at $\mathrm{m} / \mathrm{z}$ $174,244,347$ and 478 are the peaks of [HDMF] $\mathrm{Cl} / \mathrm{Zn}^{2+}$, [HDMF] $\mathrm{Cl} / \mathrm{ZnCl}_{2},[\mathrm{HDMF}]_{2} \mathrm{Cl}_{2} / \mathrm{ZnCl}_{2}$ and $2\left([\mathrm{HDMF}] \mathrm{Cl} / \mathrm{ZnCl}_{2}\right)$ losing a $\mathrm{CH}_{3}$, respectively. These results confirm that [HDMF]Cl/ $\mathrm{ZnCl}_{2}$ has been synthesized. [HDMF]Cl $\cdot 0.2 \mathrm{FeCl}_{3}$ only has anion spectrum show that all species of $[\mathrm{HDMF}] \mathrm{Cl} \cdot 0.2 \mathrm{FeCl}_{3}$ are anion.

\subsection{FTIR characterization}

Infrared spectrum peaks of $\mathrm{ZnCl}_{2}, \mathrm{FeCl}_{3}$, [HDMF]Cl, [HDMF] $\mathrm{Cl} \cdot 0.2 \mathrm{FeCl}_{3}$ and $[\mathrm{HDMF}] \mathrm{Cl} / \mathrm{ZnCl}_{2}$ have been displayed in Fig. 3 . The peaks correlated to the bending of $\mathrm{N}-\mathrm{H}$ at $665 \mathrm{~cm}^{-1}$, bending of $\mathrm{C}-\mathrm{H}$ at 887 and $1390 \mathrm{~cm}^{-1}$, the stretching vibrations of $\mathrm{C}-\mathrm{N}$ at 1021 and $1177 \mathrm{~cm}^{-1}$, and that of $\mathrm{C}=\mathrm{O}$ at 1654 and $1717 \mathrm{~cm}^{-1}$, the stretching vibration of $\mathrm{C}-\mathrm{H}$ at 2778 and $2995 \mathrm{~cm}^{-1}$, and that of $\mathrm{N}-\mathrm{H}$ at $3421 \mathrm{~cm}^{-1}$ in [HDMF]Cl are shown in Fig. 3. It can be observed that some infrared spectrumpeaks of [HDMF]Cl $\cdot 0.2 \mathrm{FeCl}_{3}$ and [HDMF]Cl are identical. Peaks of $\mathrm{FeCl}_{3}$ and $\mathrm{ZnCl}_{2}$ appear at about $550 \mathrm{~cm}^{-1}$. Meanwhile, the stretching vibration of $\mathrm{C}=\mathrm{O}$ at $1654 \mathrm{~cm}^{-1}$ strengthens and a new peak corresponding to $\mathrm{N}-\mathrm{H}-\mathrm{C}-\mathrm{N}$ at $1560 \mathrm{~cm}^{-1}$ appears in the infrared spectrum of $[\mathrm{HDMF}] \mathrm{Cl} / \mathrm{ZnCl}_{2}$. These results show that $[\mathrm{HDMF}] \mathrm{Cl}$ still retain the original structure in [HDMF] $\mathrm{Cl} \cdot 0.2 \mathrm{FeCl}_{3}$ and $[\mathrm{HDMF}] \mathrm{Cl} / \mathrm{ZnCl}_{2}$.

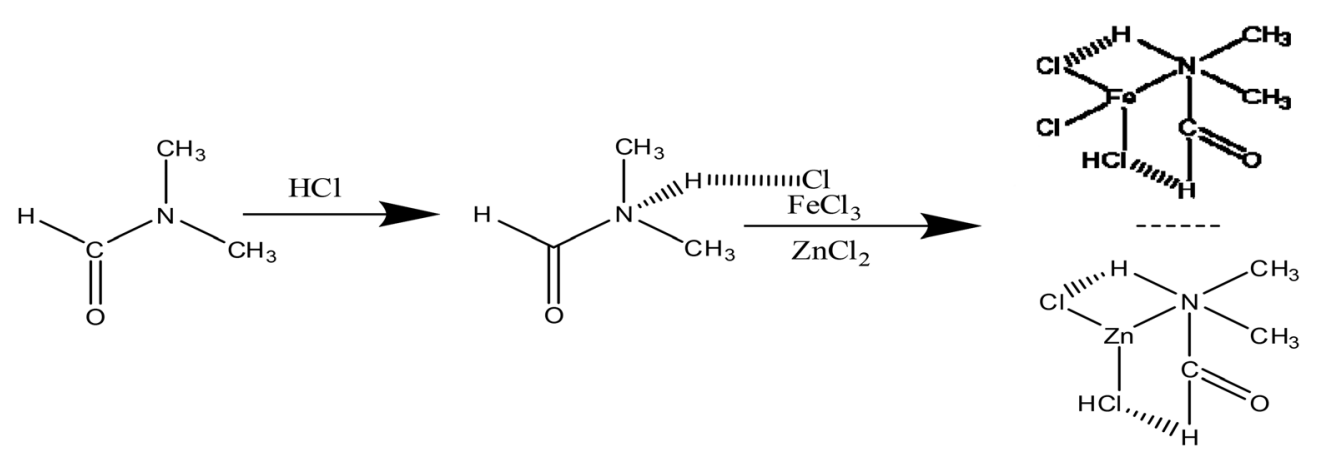

Fig. 1 Synthesis of [HDMF]Cl/XMCl . 

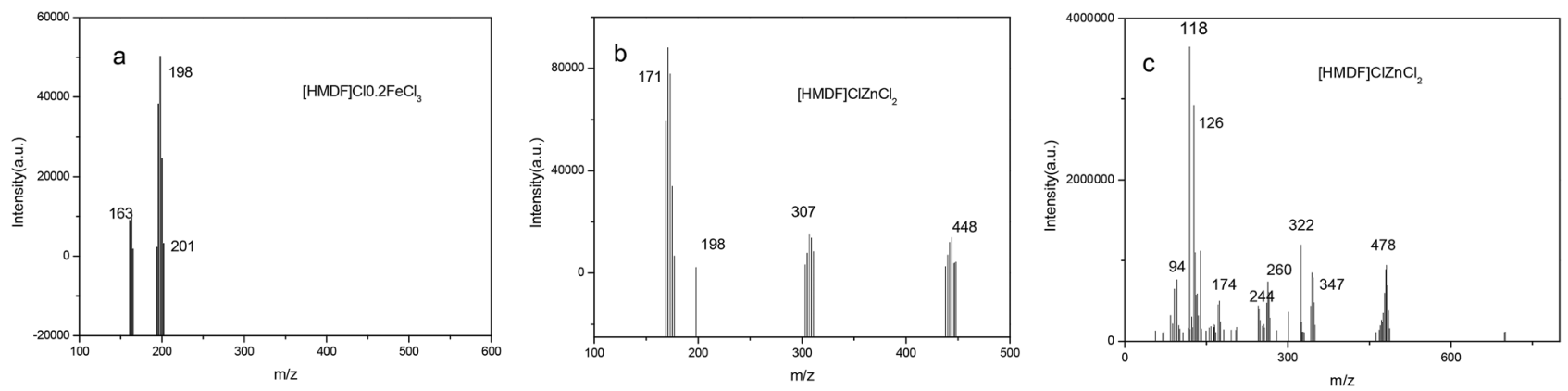

Fig. 2 ESI-MS spectra of [HDMF]Cl/0.2FeCl 3 and $[\mathrm{HDMF}] \mathrm{Cl} / \mathrm{ZnCl}_{2}$.

\subsection{Hydrogen spectrum of [ $\mathrm{HDMF}] \mathrm{Cl} / \mathbf{Z n C l}_{2}$}

The hydrogen spectrum of $[\mathrm{HDMF}] \mathrm{Cl} \cdot 0.2 \mathrm{FeCl}_{3}$ cannot be detected due to the magnetic properties of iron. The hydrogen spectrum of $[\mathrm{HDMF}] \mathrm{Cl} / \mathrm{ZnCl}_{2}$ was recorded and the results are displayed in Fig. 4. This is because the zinc chloride and [HDMF]Cl formed a hydrogen bond. The formation of hydrogen bond leads to the disappearance and the shift of hydrogen bonds in [HDMF]Cl. The $\delta=2.90$ and 8.02 are attributed to the

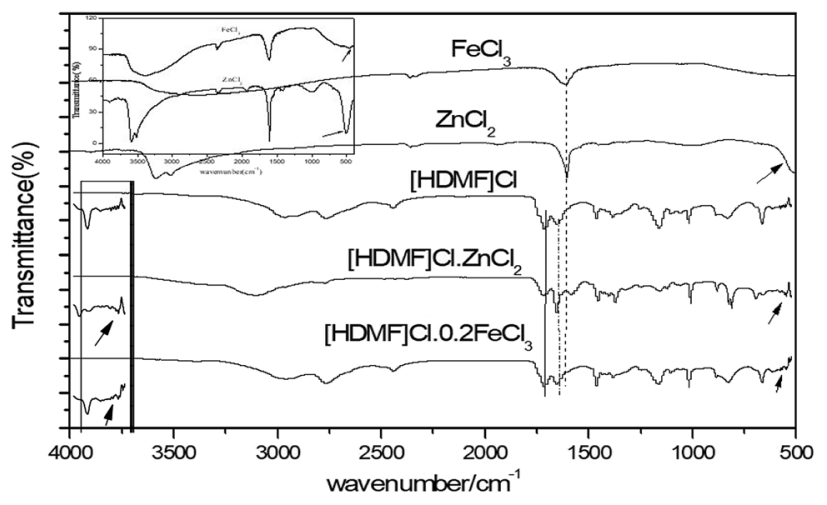

Fig. $3 \mathrm{FT}$-IR spectra of $\mathrm{FeCl}_{3}, \mathrm{ZnCl}_{2},[\mathrm{HDMF}] \mathrm{Cl}$, [HDMF]Cl$\cdot \mathrm{ZnCl}_{2}$ and [HDMF]Cl$\cdot 0.2 \mathrm{FeCl}_{3}$.

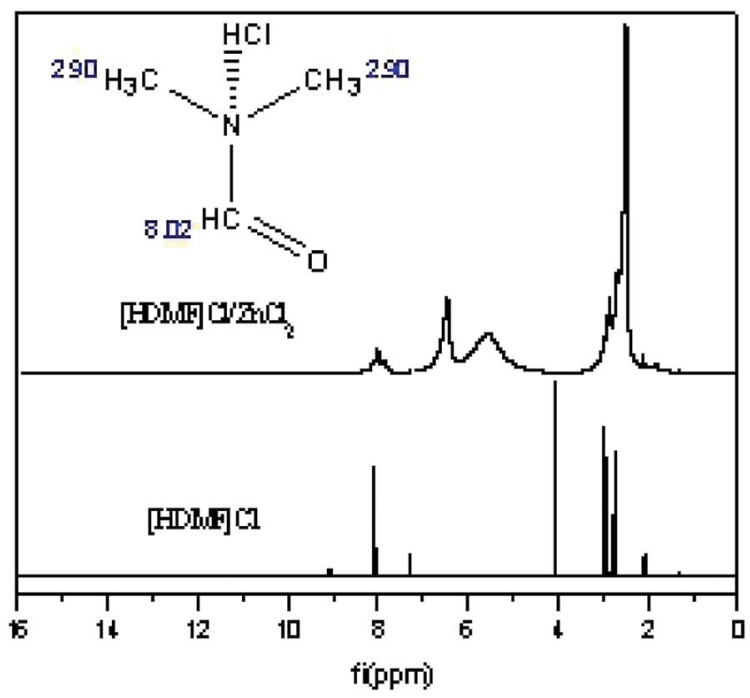

Fig. 4 Hydrogen spectrum of [HDMF]Cl/ $\mathrm{ZnCl}_{2}$. hydrogen bonds of $-\mathrm{CH}_{3}$ and $-\mathrm{CH}=\mathrm{O}$, respectively. The $\delta=4.05$ is the hydrogen bond formed between $\mathrm{N}$ and $\mathrm{HCl}$. As seen from Fig. 4, these peaks of hydrogen bonds broaden and are shifted. The new peak is attributed to the hydrogen bond between $\mathrm{Cl}$ in $\mathrm{ZnCl}_{2}$ and $\mathrm{H}$ in [HDMF]Cl. These results are also seen in another ref. 36 .

\subsection{Different desulfurization system}

In order to investigate the influence of $\mathrm{H}_{2} \mathrm{O}_{2}$, [HDMF], [HDMF] $\mathrm{Cl},[\mathrm{HDMF}] \mathrm{Cl} / \mathrm{ZnCl}_{2}$ and $[\mathrm{HDMF}] \mathrm{Cl} \cdot 0.2 \mathrm{FeCl}_{3}$ on desulfurization activity, different desulfurization systems were selected as shown in Table 1. The removal rate of DBT in model oil increased with an increase in $\mathrm{H}_{2} \mathrm{O}_{2}$ and DES. [HDMF] is a good extractant for sulfide in oil. The desulfurization rate could reach up to $75 \%$ when the volume ratio of [HDMF] and model oil was $1: 1$. The high dose of [HDMF] is harmful for the environment. Hence, $[\mathrm{HDMF}] \mathrm{Cl} / \mathrm{MCl}_{n}$ was synthesized and applied to desulfurization, and the volume ratio of [HDMF] and model oil was decreased to 0.2. As shown in Table 1, desulfurization systems of [HDMF]Cl $\cdot \mathrm{ZnCl}_{2}+\mathrm{H}_{2} \mathrm{O}_{2}$ and $[\mathrm{HDMF}] \mathrm{Cl} \cdot 0.2 \mathrm{FeCl}_{3}+\mathrm{H}_{2} \mathrm{O}_{2}$ showed excellent desulfurization activities. Lewis acids can accelerate $\mathrm{H}_{2} \mathrm{O}_{2}$ degradation to hydroxyl radicals ${ }^{35}$ in the system of oxidative desulfurization and result in high desulfurization activity. However, very high molar ratio of [HDMF]Cl to $\mathrm{MCl}_{n}$ decreased the desulfurization rate. The strong acidity accelerate decomposition of $\mathrm{H}_{2} \mathrm{O}_{2}$ (ref. 37) result in decrease of oxidant ability in the desulfurization system. Therefore, [HDMF] $\mathrm{Cl} \cdot 0.2 \mathrm{FeCl}_{3}$ and $[\mathrm{HDMF}] \mathrm{Cl} \cdot 1.0 \mathrm{ZnCl}_{2}$ are the most suitable ones for the desulfurization system. The desulfurization rates of $[\mathrm{HDMF}] \mathrm{Cl} \cdot 0.2 \mathrm{FeCl}_{3}$ and $[\mathrm{HDMF}] \mathrm{Cl} \cdot 1.0 \mathrm{ZnCl}_{2}$ are $20.36 \%$ and $15.3 \%$, respectively, without the addition of $\mathrm{H}_{2} \mathrm{O}_{2}$. However, the rates are only $9.2 \%$ and $9.6 \%$ in the system of [HDMF]Cl and [HDMF]Cl $+\mathrm{H}_{2} \mathrm{O}_{2}$, respectively. These experimental results demonstrate that $\mathrm{H}_{2} \mathrm{O}_{2}$ and Lewis acids are indispensable for the desulfurization system.

We investigated the influence of temperature, $\mathrm{O} / \mathrm{S}$, volume ratio of DES and model oil on desulfurization activity. The optimal desulfurization conditions are listed in Table 2. High temperature, $\mathrm{O} / \mathrm{S}$ molar ratio and volume ratio of DES and the model oil can accelerate the reaction rate and improve the desulfurization activity. However, very high temperature leads to the decomposition of $\mathrm{H}_{2} \mathrm{O}_{2}$ into $\mathrm{H}_{2} \mathrm{O}$ and $\mathrm{O}_{2}{ }^{38} \mathrm{~A}$ very high $\mathrm{O} / \mathrm{S}$ molar ratio results in the high production of $\mathrm{H}_{2} \mathrm{O} .{ }^{39}$ Too high 
Table 1 Influence of different Lewis acid ILs on removal rate ( $5 \mathrm{~mL}$ model oil; 6 of O/S molar ratio; $1 \mathrm{~mL}$ of DESs; $\left.40{ }^{\circ} \mathrm{C} ; 20 \mathrm{~min}\right)$

\begin{tabular}{llll}
\hline ILs & Sulfur removal $/ \%$ & & Sulfur removal/\% \\
\hline$[\mathrm{HDMF}] \mathrm{Cl} \cdot 0.1 \mathrm{FeCl}_{3}+\mathrm{H}_{2} \mathrm{O}_{2}$ & 83.46 & {$[\mathrm{HDMF}] \mathrm{Cl} \cdot 0.5 \mathrm{ZnCl}_{2}+\mathrm{H}_{2} \mathrm{O}_{2}$} & \\
{$[\mathrm{HDMF}] \mathrm{Cl} \cdot 0.2 \mathrm{FeCl}_{3}+\mathrm{H}_{2} \mathrm{O}_{2}$} & 98.08 & {$[\mathrm{HDMF}] \mathrm{Cl} \cdot 1.0 \mathrm{ZnCl}_{2}+\mathrm{H}_{2} \mathrm{O}_{2}$} & 63.8 \\
{$[\mathrm{HDMF}] \mathrm{Cl} \cdot 0.3 \mathrm{FeCl}_{3}+\mathrm{H}_{2} \mathrm{O}_{2}$} & 95.96 & {$[\mathrm{HDMF}] \mathrm{Cl} \cdot 1.5 \mathrm{ZnCl}_{2}+\mathrm{H}_{2} \mathrm{O}_{2}$} & 98.6 \\
{$[\mathrm{HDMF}] \mathrm{Cl} \cdot 0.4 \mathrm{FeCl}_{3}+\mathrm{H}_{2} \mathrm{O}_{2}$} & 62.12 & {$[\mathrm{HDMF}] \mathrm{Cl} \cdot 2 \mathrm{ZnCl}_{2}+\mathrm{H}_{2} \mathrm{O}_{2}$} & 98 \\
{$[\mathrm{HDMF}] \mathrm{Cl} \cdot 0.5 \mathrm{FeCl}_{3}+\mathrm{H}_{2} \mathrm{O}_{2}$} & 29.18 & {$[\mathrm{HDMF}] \mathrm{Cl} \cdot 1.0 \mathrm{ZnCl}_{2}$} & 87 \\
{$[\mathrm{HDMF}] \mathrm{Cl} \cdot 0.2 \mathrm{FeCl}_{3}$} & 20.36 & & 15.3 \\
{$[\mathrm{HDMF}] \mathrm{Cl}$} & & & 9.2 \\
{$[\mathrm{HDMF}] \mathrm{Cl}+\mathrm{H}_{2} \mathrm{O}_{2}$} & & & 9.6 \\
$\mathrm{~V}_{[\mathrm{HDMF}]}: \mathrm{v}_{\text {model oil }}=1: 1$, extractive desulfurization rate $=75 \%$ & &
\end{tabular}

Table 2 Optimal condition of desulfurization reaction

\begin{tabular}{lllll}
\hline Condition & [HDMF]Cl $\cdot 0.2 \mathrm{FeCl}_{3}$ & $\begin{array}{l}\text { Removal rate } \\
\text { of DBT\% }\end{array}$ & $\begin{array}{l}\text { Removal rate } \\
\text { of DBT\% } \%\end{array}$ \\
\hline$T\left({ }^{\circ} \mathrm{C}\right)$ & 40 & 98.08 & 60 & 99.21 \\
O/S & 6 & 98.12 & 6 & 99.12 \\
Volume ratio of DES/model oil & 0.2 & 98.0 & $0.15-0.2$ & 99.08 \\
$t($ min) & 30 & 98.10 & 60 & 99.16
\end{tabular}

volume ratio of DES and model oil results in more sulfide being extracted into the DES phase, resulting in the decrease of $\mathrm{O} / \mathrm{S}$ molar ratio. This reduces the desulfurization activity of the system. Thus, the optimal conditions of desulfurization are listed in Table 2.

\subsection{Influence of different sulfur compounds on the desulfurization system}

To investigate the influence of $[\mathrm{HDMF}] \mathrm{Cl} \cdot 0.2 \mathrm{FeCl}_{3}-\mathrm{H}_{2} \mathrm{O}_{2}$ and [HDMF]Cl/ $\mathrm{ZnCl}_{2}-\mathrm{H}_{2} \mathrm{O}_{2}$ on the different sulfur compounds, four sulfur compounds, namely, as DBT, 4,6-DMDBT, BT and TH were selected and the reactions were carried out under optimal conditions. From the ref. 40, it was known that the order of electron cloud density is 4,6-DMDBT (5.760) > DBT (5.758) > BT (5.739) $>$ TH (5.696). As shown in Table 3, the order of oxidative desulfurization is DBT $>4,6$-DMDBT $>$ BT $>$ TH in the systems of $[\mathrm{HDMF}] \mathrm{Cl} \cdot 0.2 \mathrm{FeCl}_{3}-\mathrm{H}_{2} \mathrm{O}_{2}$ and $[\mathrm{HDMF}] \mathrm{Cl} / \mathrm{ZnCl}_{2}-\mathrm{H}_{2} \mathrm{O}_{2}$. It can be concluded that the bigger electron cloud density can easily remove sulfur. The electron cloud densities of DBT and 4,6DMDBT were 5.758 and 5.760, respectively. The desulfurization rate of DBT was higher than that of 4,6-DMDBT. This could be attributed to the steric hindrance of two methyls of 4,6-DMDBT, which inturn hinders the desulfurization reaction.

\subsection{Recovery-regeneration of ILs}

The upper oil phase was removed using a separating funnel after the oxidative desulfurization reaction. The water in the DES was removed by rotary evaporation. The DES was extracted three times using carbon tetrachloride $\left(\mathrm{CCl}_{4}\right)$ of equal volume. The recycling experiments were carried out by adding fresh $\mathrm{H}_{2} \mathrm{O}_{2}$, model oil, and the recovered DES at the optimal conditions. As shown in Table 4, the desulfurization activity of [HDMF] $\mathrm{Cl} \cdot 0.2 \mathrm{FeCl}_{3}$ decreased from $98.08 \%$ to $96.01 \%$, and the desulfurization rate of [HDMF] $\mathrm{Cl} / \mathrm{ZnCl}_{2}$ decreased from $99.2 \%$ to $97.6 \%$ after seven cycles. This can be attributed to a little loss of DES and the residual oxidation products of DBT in the DES during the recovery process.

\subsection{FT-IR characterization of oxidation products}

According to the above experiment, DES was extracted by $\mathrm{CCl}_{4}$. Then, $\mathrm{CCl}_{4}$ was removed by rotary evaporation. Thereafter, a white powder was obtained. The infrared analysis of the white powder is shown in Fig. 5 . The three infrared absorption peaks at 1166,1047 and $1288 \mathrm{~cm}^{-1}$ correspond to the three characterization peaks of dibenzothiophene sulfone $\left(\mathrm{DBTO}_{2}\right)^{35,41,42} \mathrm{It}$ can be concluded that the oxidation product was $\mathrm{DBTO}_{2}$ in the oxidative desulfurization system. DES was analyzed by FT-IR

Table 3 Desulfurization rate of different sulfides

\begin{tabular}{lllll}
\hline & {$[\mathrm{HDMF}] \mathrm{Cl} \cdot 0.2 \mathrm{FeCl}_{3} t(\mathrm{~min})$} & Removal rate\% & {$[\mathrm{HDMF}] \mathrm{Cl} / \mathrm{ZnCl}_{2} t($ time $)$} & $\mathrm{Removal} \mathrm{rate} \%$ \\
\hline DBT & 30 & 98.08 & 60 & 99.2 \\
4,6 DMDBT & 30 & 95.4 & 120 & 95.6 \\
BT & 60 & 42.99 & 140 & 54.6 \\
HT & 30 & 13.91 & 140 & 26.5
\end{tabular}


Table 4 Influence of IL recycling on desulfurization rate

\begin{tabular}{lll}
\hline Recycle time $/ n$ & {$[\mathrm{HDMF}] \mathrm{Cl} \cdot 0.2 \mathrm{FeCl}_{3}$} & {$[\mathrm{HDMF}] \mathrm{Cl} / \mathrm{ZnCl}_{2}$} \\
\hline 1 & 98.08 & 99.2 \\
2 & 97.95 & 99.1 \\
3 & 97.69 & 98.9 \\
4 & 97.31 & 98.8 \\
5 & 97.04 & 98.5 \\
6 & 96.74 & 98.3 \\
7 & 96.01 & 97.6
\end{tabular}

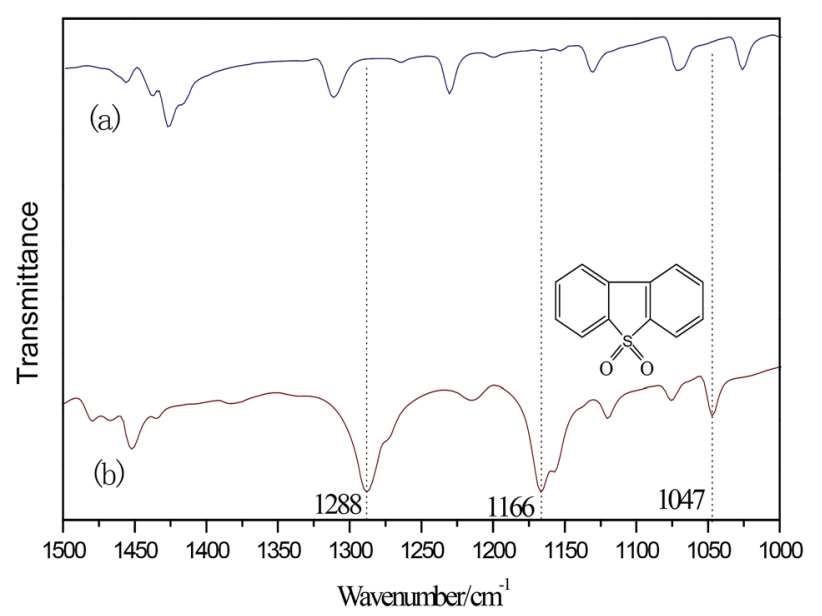

Fig. 5 Spectra of infrared analysis for (a) DBT, (b) $\mathrm{DBTO}_{2}$.

spectroscopy in order to study its stability. From Fig. 6, the FTIR spectrum of used DES shows peaks at 665, 887, 1390, 1021, $1177,1654,1717,2778,2995$ and $3424 \mathrm{~cm}^{-1}$. The new peak at $3424 \mathrm{~cm}^{-1}$ is the stretching vibration of $\mathrm{OH}$. This shows that the used DES absorbs a little bit of water in air. Water also can decrease the activity of DES, resulting in the decrease of desulfurization rate.

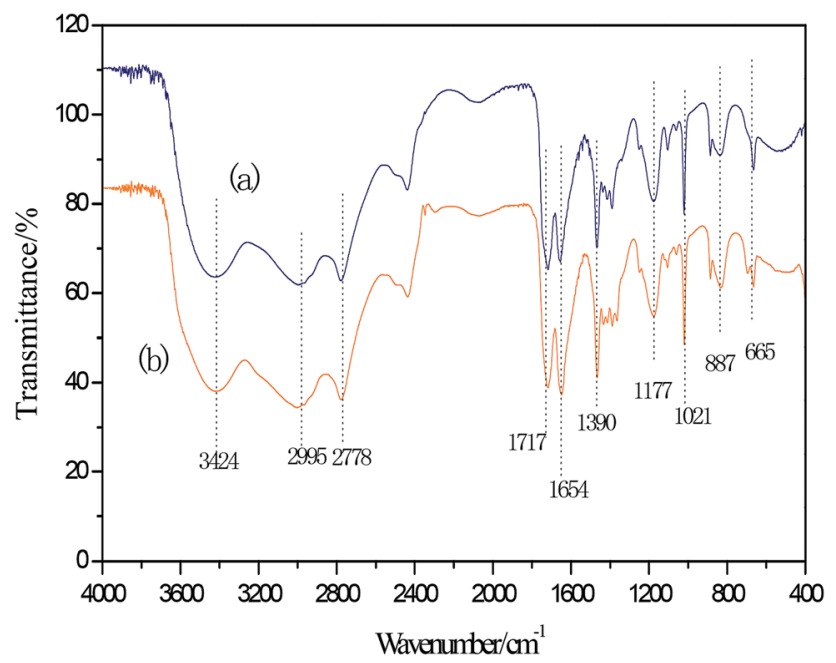

Fig. 6 FT-IR analysis of used DES of (a) [HDMF]Cl-0.2 $\mathrm{FeCl}_{3}$, (b) [HDMF] $\mathrm{Cl} / \mathrm{ZnCl}_{2}$.

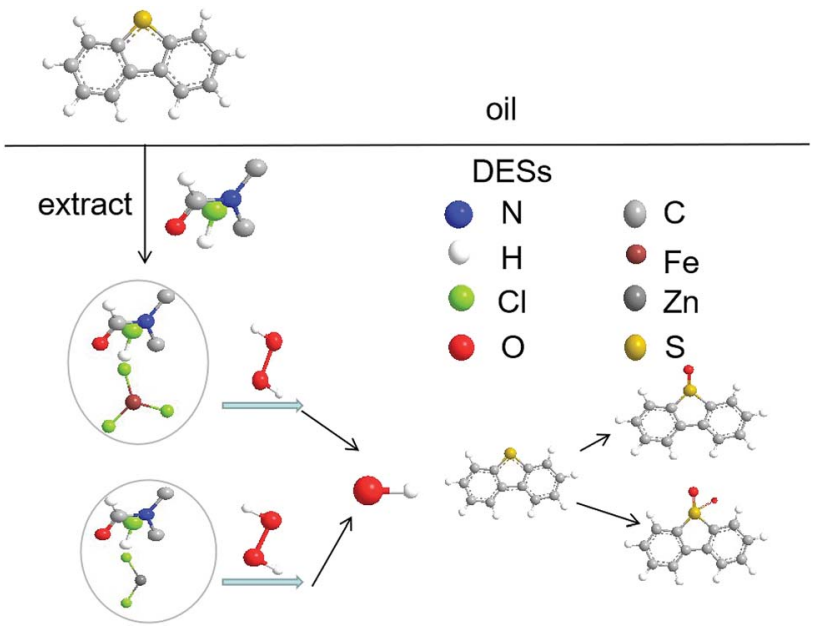

Fig. 7 Mechanism of the catalytic oxidative desulfurization.

\subsection{Mechanism of catalyzed oxidative desulfurization}

DBT in model oil was chosen as a representative of sulfur compounds in the oxidative desulfurization system. DBT in model oil was partially extracted by the DMF of DES. $\mathrm{FeCl}_{3}$ and $\mathrm{ZnCl}_{2}$ can catalyze $\mathrm{H}_{2} \mathrm{O}_{2}$ to produce hydroxyl radicals $\left({ }^{\circ} \mathrm{OH}\right)$. Hydroxyl radicals as a strong oxidant can oxidize DBT into dibenzothiophene sulfone $\left(\mathrm{DBTO}_{2}\right)$. DBT continued to be extracted and oxidized in the subsequent cycles until DBT was completely transformed to $\mathrm{DBTO}_{2}$. The mechanism ${ }^{43-45}$ of the catalytic oxidative desulfurization is shown in Fig. 7.

\section{Conclusion}

In this work, $[\mathrm{HDMF}] \mathrm{Cl} / \mathrm{XMCl}_{n}$ was synthesized by a stirring method at low temperature. The sulfur compounds in the model oil were removed using DES as the extractant and catalyst, and $\mathrm{H}_{2} \mathrm{O}_{2}$ as the oxidant. The experimental results showed that at a low $\mathrm{O} / \mathrm{S}$ molar ratio and low volume ratio of DES/model oil, the desulfurization rates of $[\mathrm{HDMF}] \mathrm{Cl} \cdot 0.2 \mathrm{FeCl}_{3}$ and $[\mathrm{HDMF}]$ $\mathrm{Cl} \cdot \mathrm{ZnCl}_{2}$ can be achieved up to $98.08 \%$ and $99.2 \%$, respectively. Two systems of desulfurization saved lots of $\mathrm{N}, \mathrm{N}$-dimethylformamide and improved the desulfurization activities. Moreover, $[\mathrm{HDMF}] \mathrm{Cl} \cdot 0.2 \mathrm{FeCl}_{3}$ can attain high desulfurization rate within a short time at low temperature.

\section{Conflicts of interest}

There are no conflicts to declare.

\section{Acknowledgements}

The authors acknowledge the financial support of the Natural Science Foundation of China (Project no. 21003069) and Doctoral Fund of Liaoning Province (201501105).

\section{References}

1 W. N. W. Abdullah, W. A. Bakar and R. Ali, Catalytic oxidative desulfurization of diesel fuel utilizing a polymolybdate 
alumina supported catalyst: characterization, catalytic activity and mechanistic study, React. Kinet., Mech. Catal., 2015, 114(2), 547-560.

2 J. Zhang, W. Zhu, H. Li, et al., Deep oxidative desulfurization of fuels by Fenton-like reagent in ionic liquids, Green Chem., 2009, 11(11), 1801-1807.

3 S. Brunet, D. Mey, G. Pérot, et al., On the hydrodesulfurization of FCC gasoline: a review, Appl. Catal., A, 2005, 278(2), 143-172.

4 H. Lü, J. Gao, Z. Jiang, et al., Ultra-deep desulfurization of diesel by selective oxidation with $\left[\mathrm{C}_{18} \mathrm{H}_{37} \mathrm{~N}\left(\mathrm{CH}_{3}\right)_{3}\right]_{4}\left[\mathrm{H}_{2} \mathrm{NaPW}_{10} \mathrm{O}_{36}\right]$ catalyst assembled in emulsion droplets, J. Catal., 2006, 239(2), 369-375.

5 C. Shen, Y. J. Wang, J. H. Xu, et al., Synthesis of TS-1 on porous glass beads for catalytic oxidative desulfurization, Chem. Eng. J., 2015, 259, 552-561.

$6 \mathrm{~J}$. Gao, X. Chen, N. Ren, et al., Acylation desulfurization of oil via reactive adsorption, AIChE J., 2013, 59(8), 2966-2976.

7 G. Miao, F. Ye, L. Wu, et al., Selective adsorption of thiophenic compounds from fuel over $\mathrm{TiO}_{2} / \mathrm{SiO}_{2}$ under UVirradiation, J. Hazard. Mater., 2015, 300, 426-432.

8 C. Wang, Z. Chen, X. Yao, et al., Decavanadates anchored into micropores of graphene-like boron nitride: efficient heterogeneous catalysts for aerobic oxidative desulfurization, Fuel, 2018, 230, 104-112.

$9 \mathrm{~W}$. Zhu, P. Wu, L. Yang, et al., Pyridinium-based temperature-responsive magnetic ionic liquid for oxidative desulfurization of fuels, Chem. Eng. J., 2013, 229, 250-256.

10 W. Zhu, C. Wang, H. Li, et al., One-pot extraction combined with metal-free photochemical aerobic oxidative desulfurization in deep eutectic solvent, Green Chem., 2015, 17(4), 2464-2472.

$11 \mathrm{M}$. Soleimani, A. Bassi and A. Margaritis, Biodesulfurization of refractory organic sulfur compounds in fossil fuels, Biotechnol. Adv., 2007, 25(6), 570-596.

$12 \mathrm{H}$. Gao, S. Zeng, X. Liu, et al., Extractive desulfurization of fuel using N-butylpyridinium-based ionic liquids, $R S C A d v$., 2015, 5(38), 30234-30238.

13 H. Lü, J. Gao, Z. Jiang, et al., Oxidative desulfurization of dibenzothiophene with molecular oxygen using emulsion catalysis, Chem. Commun., 2007, (2), 150-152.

14 S. S. Cheng and T. F. Yen, Use of ionic liquids as phasetransfer catalysis for deep oxygenative desulfurization, Energy Fuels, 2008, 22(2), 1400-1401.

15 P. S. Tam, J. R. Kittrell and J. W. Eldridge, Desulfurization of fuel oil by oxidation and extraction. 1. Enhancement of extraction oil yield, Ind. Eng. Chem. Res., 1990, 29(3), 321324.

16 P. De Filippis and M. Scarsella, Functionalized hexagonal mesoporous silica as an oxidizing agent for the oxidative desulfurization of organosulfur compounds, Ind. Eng. Chem. Res., 2008, 47(3), 973-975.

17 A. Arce, M. Francisco and A. Soto, Evaluation of the polysubstituted pyridinium ionic liquid $[\mathrm{hmmpy}]\left[\mathrm{Ntf}_{2}\right]$ as a suitable solvent for desulfurization: phase equilibria, $J$. Chem. Thermodyn., 2010, 42(6), 712-718.
18 J. Ranke, S. Stolte, R. Störmann, et al., Design of sustainable chemical products the example of ionic liquids, Chem. Rev., 2007, 107(6), 2183-2206.

19 Y. Nie, C. Li, A. Sun, et al., Extractive desulfurization of gasoline using imidazolium-based phosphoric ionic liquids, Energy Fuels, 2006, 20(5), 2083-2087.

20 M. A. P. Martins, C. P. Frizzo, D. N. Moreira, et al., Ionic liquids in heterocyclic synthesis, Chem. Rev., 2008, 108(6), 2015-2050.

21 L. Zhang, Y. Cui, C. Zhang, et al., Biodiesel production by esterification of oleic acid over brønsted acidic ionic liquid supported onto Fe-incorporated SBA-15, Ind. Eng. Chem. Res., 2012, 51(51), 16590-16596.

22 H. Lü, C. Deng, W. Ren, et al., Oxidative desulfurization of model diesel using $\left[\left(\mathrm{C}_{4} \mathrm{H}_{9}\right)_{4} \mathrm{~N}\right]_{6} \mathrm{Mo}_{7} \mathrm{O}_{24}$ as a catalyst in ionic liquids, Fuel Process. Technol., 2014, 119, 87-91.

23 Q. Wang, L. Lei, J. Zhu, et al., Deep desulfurization of fuels by extraction with 4-dimethyl- aminopyridinium-based ionic liquids, Energy Fuels, 2013, 27(8), 4617-4623.

24 N. Liu, F. Luo, H. Wu, et al., One-step ionic-liquid-assisted electrochemical synthesis of ionic-liquid-functionalized graphene sheets directly from graphite, Adv. Funct. Mater., 2008, 18(10), 1518-1525.

25 A. Bösmann, L. Datsevich, A. Jess, et al., Deep desulfurization of diesel fuel by extraction with ionic liquids, Chem. Commun., 2001, (23), 2494-2495.

26 S. Zhang, Q. Zhang and Z. C. Zhang, Extractive desulfurization and denitrogenation of fuels using ionic liquids, Ind. Eng. Chem. Res., 2004, 43(2), 614-622.

27 C. Huang, B. Chen, J. Zhang, et al., Desulfurization of gasoline by extraction with new ionic liquids, Energy Fuels, 2004, 18(6), 1862-1864.

28 L. Alonso, A. Arce, M. Francisco, et al., Solvent extraction of thiophene from n-alkanes $\left(\mathrm{C}_{7}, \mathrm{C}_{12}\right.$, and $\left.\mathrm{C}_{16}\right)$ using the ionic liquid $\left[\mathrm{C}_{8} \mathrm{mim}\right]\left[\mathrm{BF}_{4}\right]$, J. Chem. Thermodyn., 2008, 40(6), 966972.

29 F. Li, Y. Liu, Z. Sun, et al., Deep Extractive Desulfurization of Gasoline with $\mathrm{xEt}_{3} \mathrm{NHCl} \cdot \mathrm{FeCl}_{3}$ Ionic Liquids, Energy Fuels, 2010, 24(8), 4285-4289.

30 X. Chen, H. Guo, A. A. Abdeltawab, et al., Brønsted-Lewis Acidic Ionic Liquids and Application in Oxidative Desulfurization of Diesel Fuel, Energy Fuels, 2015, 29(5), 2998-3003.

$31 \mathrm{~F} . \mathrm{Li}, \mathrm{B} . \mathrm{Wu}, \mathrm{R}$. Liu, et al., An inexpensive N-methyl-2pyrrolidone-based ionic liquid as efficient extractant and catalyst for desulfurization of Dibenzothiophene, Chem. Eng. J., 2015, 274, 192-199.

32 X. Chen, D. Song, C. Asumana, et al., Deep oxidative desulfurization of diesel fuels by Lewis acidic ionic liquids based on 1-n-butyl-3-methylimidazolium metal Chloride, $J$. Mol. Catal. A: Chem., 2012, 359, 8-13.

33 Y. Dong, Y. Nie and Q. Zhou, Highly efficient oxidative desulfurization of fuels by Lewis acidic ionic liquids based on iron chloride, Chem. Eng. Technol., 2013, 36(3), 435-442.

34 L. F. Ramirez-Verduzco, E. Torres-Garcia, R. GomezQuintana, et al., Desulfurization of diesel by oxidation/ 
extraction scheme: influence of the extraction solvent, Catal. Today, 2004, 98(1), 289-294.

35 S. Otsuki, T. Nonaka, N. Takashima, et al., Oxidative desulfurization of light gas oil and vacuum gas oil by oxidation and solvent extraction, Energy Fuels, 2000, 14(6), 1232-1239.

36 Y. Nie, X. Gong, H. S. Gao, et al., Simultaneous desulfurization and denitrogen of liquid fuels using two functionalized group ionic liquids, Sci. China: Chem., 2014, 57(12), 1766-1773.

37 Y. Jiang, W. Zhu, H. Li, et al., Oxidative Desulfurization of Fuels Catalyzed by Fenton-Like Ionic Liquids at Room Temperature, ChemSusChem, 2011, 4(3), 399-403.

38 W. Zhu, H. Li, X. Jiang, et al., Commercially available molybdic compound-catalyzed ultra-deep desulfurization of fuels in ionic liquids, Green Chem., 2008, 10(6), 641-646.

39 W. Jiang, W. Zhu, H. Li, et al., Deep oxidative desulfurization of fuels catalyzed by magnetic Fenton-like hybrid catalysts in ionic liquids, $R S C A d v ., 2013,3(7), 2355-2361$.
40 C. Komintarachat and W. Trakarnpruk, Oxidative desulfurization using Polyoxometalates, Ind. Eng. Chem. Res., 2006, 45(6), 1853-1856.

41 C. Mao, R. Zhao, X. Li, et al., Trifluoromethanesulfonic acidbased DESs as extractants and catalysts for removal of DBT from model oil, RSC Adv., 2017, 7(21), 12805-12811.

42 M. Zhang, W. Zhu, S. Xun, et al., Deep oxidative desulfurization of dibenzothiophene with POM-based hybrid materials in ionic liquids, Chem. Eng. J., 2013, 220, 328-336.

43 J. Zhang, W. Zhu, H. Li, et al., Deep oxidative desulfurization of fuels by Fenton-like reagent in ionic liquids, Green Chem., 2009, 11(11), 1801-1807.

44 Y. Nie, X. Gong, H. S. Gao, et al., Simultaneous desulfurization and denitrogen of liquid fuels using two functionalized group ionic liquids, Sci. China: Chem., 2014, 57(12), 1766-1773.

45 H. Azimzadeh, A. Akbari and M. R. Omidkhah, Catalytic oxidative desulfurization performance of immobilized NMP. $\mathrm{FeCl}_{3}$ ionic liquid on $\gamma-\mathrm{Al}_{2} \mathrm{O}_{3}$ support, Chem. Eng. J., 2017, 320, 189-200. 